\title{
A Mountaineering Expedition to the Himalaya of Garhwal: Discussion
}

Author(s): Mr. Freshfield, Mr. Mumm, H. Woolley, Thomas Holdich, Martin Conway, Prof. Garwood and T. G. Longstaff

Source: The Geographical Journal, Vol. 31, No. 4 (Apr., 1908), pp. 389-395

Published by: geographicalj

Stable URL: http://www.jstor.org/stable/1777842

Accessed: 27-06-2016 03:04 UTC

Your use of the JSTOR archive indicates your acceptance of the Terms \& Conditions of Use, available at

http://about.jstor.org/terms

JSTOR is a not-for-profit service that helps scholars, researchers, and students discover, use, and build upon a wide range of content in a trusted digital archive. We use information technology and tools to increase productivity and facilitate new forms of scholarship. For more information about JSTOR, please contact support@jstor.org.

The Royal Geographical Society (with the Institute of British Geographers), Wiley are collaborating with JSTOR to digitize, preserve and extend access to The Geographical Journal 
Before the paper, the Chairman (Mr. Freshfield, Vice-President) said: The paper $t$ s be read to-night is on explorations in the Himalaya. Since it is only two months ago that we had a very interesting paper from Dr. Workman on his explorations in the Himalaya, it may seem to you somewhat soon to return to the same region. But I may point out, I will not say excuses, but reasons why we should find ourselves paying more frequent attention to the mountainous portions of the globe. As exploration goes on, the level, or comparatively level, regions are naturally the soonest exhausted, and adventurers turn to the unexplored regions, either to the snows of the Poles or the snows of the Peaks. 'There is another reason which I might allege: that the Himalaya is a term which covers an exceedingly wide tract of country. I would not impute to any Fellow present any lack of intimate knowledge of the Himalaya, but I cannot but recollect that in this hall I was asked, when I went to Kangchenjunga a few years ago, whether I had been treading in the track of Sir Martin Conway. Now, the distance between Kangchenjunga and the scene of Sir Martin Conway's travels is equivalent to that between the Gross Glockner in Carinthia and Mont Perdu in the heart of the Pyrenees. Therefore, though we may be talking about the Himalaya, we are not talking about the same region. Dr. Longstaff's paper is a description of a district in the centre of the Himalaya, roughly speaking, nurth of Agra. If you look for it in your atlases, you will find it just to the west of that long green caterpillar that crawls along the back of India, the native state of Nepal.

With regard to the author of the paper, he does not require any introduction to this audience. He must be doubly welcome, first as the son of a father who, when His Majesty's late Government found themselves inadequate to support the great Antarctic Expedition, made it a possibility, and secondly, because we already know Dr. Longstaff here. He published a paper in the Geographical Journal of February, 1907, on his previous Himalayan journey in company with Mr. Sherring. The present expedition is, I should remind you, the result of the proposal, the unfortunately unsuccessful proposal, that was made to His Majesty's present Government, that an expedition should be sent, at no cost to the nation, but entirely at the cost of those who were undertaking it, to explore the neighbourhood of Mount Everest, and to ascertain the accessibility of the highest mountain in the world. When the present Cabinet refused leave to that expedition, the members of the Alpine Club who were prepared to undertake it diverted their thoughts to something of a more modest kind, and set out on the journey of which I will now call upon Dr. Longstaff to give you an account.

After the paper, Mr. FreshField said: I have listened with very great pleasure to the graphic description which Dr. Longstaff has given us of an Himalayan district, one of the most graphic descriptions we have ever had in this Society. I am sure we have all followed his adventures with the keenest interest, and that I am only interpreting the sentiments of every one here present in saying that we have thoroughly enjoyed his lecture and the most beautiful series of photographs which he has put before us to-night. My ouly regret is that since-we are preeminently an Early Closing Association, Dr. Longstaff has been unable to give us the solid results of his journey, the mass of observations, geographical and topographical, which he and his companions have made. However, I remember what Sir Ruderick Murchison sald to me forty years ago, when I first read a paper before the Society. "Tell them your adventures, and print your results." And fortunately we shall have the advantage of reading in an early number of the Journal the full results of this remarkable expedition. Dr. Longstaff and his companions have done a very solid pitce of work, and they have been fortunate in crowning it by an exploit, which may perhaps be more appreciated at the Alpine 
Club than it is here, the conquest of Trisul. That mountain has two advantages : in the first place, it has been triangulated, and therefore there can be no dispute as to its height; and, in the second place, it is one of the historical, perhaps I should rather say one of the legendary, peaks of India, one of those great pinnacles of everlasting snow which look down upon the heated inhabitarts of the plains, and are associated by them with the Abode of Deity. I am sure I shall also interpret the sense of this meeting, if I express our keen sympathy with Dr. Longstaff's companions, Major Bruce, who has done more, perhaps, than any man for Hinalayan exploration by his training of the Gurkhas, and also with Mr. Mumm, for the unfortunate, though happily temporary accidents, which prevented them both from taking part in that crowning mercy, the ascent of Trisul.

Dr. Longstaff has, like all Himalayan travellers, had to suggest corrections in the topographical detail of Survey maps. I have said Himalayan travellers, but I might have dropped the adjective, for all mountaineers bave to do the same thing. If Napoleon the Great was the founder of European cartography in the political sense, General Dufour was the founder of scientific mountain cartography. The Swiss Survey is the only one in which extensive alterations have not had to be made since the snows came to be explored by mountaineers. Twenty-five years ago, when mountaineers first went to India, they no doubt, some of them, expressed their criticisms crudely. They were misunderstood, and a certain amount of antagonism was excited between surveyors and climbers. All that has happily long passed away, and, if they sometimes criticize, there are no people in the world so well able to appreciate the merits of the Indian maps and the difficulties under which they were constructed as those who wander among the hitherto inaccessible recesses of the mountains. One of the first-fruits of the cordial understanding that now exists is the fact I mentioned here some months ago, that the Geological Survey of India are undertaking a series of measurements of the movements of glaciers, such as were first instituted by the Alpine Club in Europe. There is a further suggestion I should like to make-that the idea of starting in India an Himalayan Club, first suggested by the Kashmir surveyor, Mr. Johnson, should be followed up. Such a body might do a greai deal, by collecting observations and by publishing a journal, to assist mountaineers; it might study the question of reaching the highest altitudes. I have several suggestions that I might make as to how any attempt should be made to reach 29,000 feet, but I see among the audience my friend Mr. Woolley, President of the Alpine Club, and I will leave that branch of the subject to him.

I notice that at the last meeting, when we discussed the Himalaya, Dr. Longstaff referred, as he has again to-night, to Mr. Graham's ascents. These ascents were made too early. Twenty-five years ago they were ridiculed in India, and they are still disbelieved by many people, whose opinion is worthy of consideration, in this country. This was to a great extent Mr. Graham's own fault. He described his travels without any of the precision in detail which is expected of the modern explorer. But as I was mainly responsible for bringing them before the attention of this Society, I must confess to having felt a certain satisfaction in finding that the two main grounds upon which they have been disputed have fallen through. One ground was that it was impossible to climb above 20,000 feet at the pace at which Mr. Graham said he climbed. Dr. Longstaff has climbed faster at the same altitude. The second was, that Kabru was an inaccessible mountain. Now, on October 20 last two Norwegians climbed to the summit ridge of Kabru. With regard to these two plucky Norwegians, I would add a few words. They reached the summit ridge of Kabru between the two peaks, but did not go to either top. They started too late, and they had much step-cutting, and 
time prevented them. They climbed apparently to 23,800 or 23,900 feet. But do not fear that I am going to trouble you with any discussion about records. I was born before records were invented, and if an old mountaineer may give advice to his younger friends, I would strongly recommend them to follow Dr. Longstaff's example-not to insist too much on records, to think more of getting to the tops of their peaks, and less of getting higher than their rivals. For a record in mountaineering is, after all, a very fleeting possession, a very transitory joy. The spirit of the Alpine Club has never been, if I may say so, one of selfadvertisement or of jealousy; it has rather been one which might be expressed in the words (slightly altered) of a living poet, the Poet Laureate of the English race, Mr. Rudyard Kipling-

"And no one shall climb for money, and no one shall climb for fame, But each for the joy of the climbing."

And I would add, for the memory of it in after-years.

I will now ask Dr. Longstaff's companion, Mr. Mumm, to address us.

Mr. Mumm : There are two things I wish to say to persons about to go mountaineering in Garhwal : first, they should take the precaution of being somewhere between twenty-eight and thirty-five years of age, and, secondly, they should concentrate, and not try to cover too much ground. It was largely due to my neglect of the first of these points that I did so little climbing in the first part of my journey; it was disregard of the second which led to none of us doing very much in the second stage of it. Of course, in a new country which one is not likely to return to, it is very tempting to try to see as much of it as possible, and I am not sure that I did not get as nuch pleasure from our actual wanderings as I should have done if we had wandered less and climbed more. But you cannot have it both ways. In the Alps you can have it both ways. You can go over glacier passes or traverse the tops of peaks, and need never sleep two nights in the same hotel. But when you have got to carry your hotel about with you, it is a different matter. There is a magnificent field in Garhwal for mountain travel of both kinds. For the wanderer there are the great glaciers, all abounding in superb scenery, and many still wholly unknown and full of surprises. They are most of them very accessible; indeed, their moraines are almost the only places in Garhwal along which you get a decent place to walk. As for the climbing possibilities, they are simply limitless; but if you want to climb, you must, as I said, concentrate, and you must not yield too much to the spell of the great giants. I think Kamet was to our party rather a will o' the wisp. Our Italian guides, the Brocherels, were always pining to go to the top of something: they didn't trouble themselves as to whether it was 23,000 or 21,000 feet, nor as to whether it had a name or not. Their attitude was, "Here are the mountains: they are big, they are difficult, no one has been up them; what more can anybody want?" I think this attitude is the one most likely to lead to successful climbing in the Himalaya. I should myself like nothing better than to return to Garhwal in that frame of mind, and I have a beautiful programme for my next visit. I should not go near Kamet or Nanda Devi; there would be lots of climbing, and I should only shift my camp twice, one day's march each time. I should finish up at the glacier above Gamsali, which I have a special reason for wishing to revisit. I did go up it for a considerable distance, and I had a very curious experience. It was very much as if one had started from the Furca Hotel to explore the Rhone glacier, relying on a map which showed that the upper part of the glacier was surrounded by a circle of rocky mountains, and one found instead that the glacier went down the other side and disappeared round the corner on the way to the Gadmenthal. That, of course, 
is what you do find when you go up the Rhone glacier; I am not prepared to guarantee that the same thing happens with the glacier above Gamsali, but that is what it loozed like. I had to shelter from a snowstorm for a long time, and when I got to the point from which this unexpected behaviour of the glacier was visible, it was too late to go any further, and so that little topographical problem had to be left unsolved. I have referred to it, partly because it is a good illustration of what I was saying about the interest attaching to glacier exploration in these regions, partly also because it is the one interesting thing that I found out all by myself. The clearing up of that problem will be the last of the agenda on my programme next time I go to Garhwal. Only I am afraid there never will be a next time. 1

Mr. H. WoolleY : I regret not to be able to make any important comment on the very interesting description to which we have listened, as I have never ascended to a greater height than 18,500 feet, and have never suffered directly from the effects of diminished atmospheric pressure, whereas I believe that the serious effects of an insufficient supply of oxygen begin, with a man in good training, at about 20,000 feet. The problem with regard to the height attainable by a pedestrian has reached a very interesting stage. Taking the highest point gained hitherto at 24,000 feet, Dr. Workman, who gave us an address here some weeks ago, seems to think that, owing to the great loss of strength and vitality due to the difficulty of respiration, the limit will be reached, even on an easy gradient, within the next 3000 or 4000 feet. Dr. Longstaff is more hopeful, and his party did not seem to be affected to anything like the same degree as Dr. Workman's party. But Dr. Longstaff will probably admit that in order to reach the higher summits-say of 26,000 feet and upwards-it will be necessary to have two parties. The first party, as lightly equipped as practicable, will complete the final ascent; the second party, also composed of experts, will accompany the first party as far as possible, and up to that point keep them supplied with necessaries, and relieve them of all labour except the actual labour of locomotion. It will be interesting if an experiment on these lines can be tried on a mountain presenting no very great climbing difficulties. Dr. Longstaff's photographs were very beautiful and instructive, and some of the most striking views were those of the gorges showing what a wonderfully effective cutting instrument a mountain torrent is. I have listened to the description this evening with the greatest interest arid pleasure, and am very glad to have this opportunity of congratulating Dr. Longstaff on his notable ascent of Trisul.

Sir Thomas Holdich : I have nothing but admiration to express for the energy and the ability which Dr. Longstaff has shown in conducting this very remarkable expedition, and nothing but admiration for those splendid photographs, which incidentally prove most conclusively that he certainly did ascend to the extreme summit of Trisul. But there is just one point which I should like to make toright, and it is a point which was suggested to me. As I was leaving the office of the R.G.S. this afternoon, and passing through the Burlington Arcade, in that classic spot I met an ex-Surveyor-General who suggested to me that, as it is impossible, and has always been impossible, for the Survey Department of India to undertake the topographical survey of such remote regions as have been visited by Dr. Longstaff, it might be well if we could press some of these Himalayan climbers into our service in order to obtain certain scientific observations which would be of the utmost value in future. I need not remind you that barometrical observations for altitude are really of very little value. I do not say that they are of no value, because certainly in the absence of any other method of determining altitudes, they are better than nothing ; but an observation taken trigonometrically, 
that is to say, by an observed altitude from a known height, is a far more conclusive observation for finding the altitude of a distant peak than any barometric determination. Trisul is one of those peaks of the Himalayas which has been exceedingly well fixed. We know precisely its position, and its altitude almost exactly; I say almost because there are certain corrections, certain weaknesses about those observations, which require eliminating, and the greatest weakness is the fact that we never know exactly what tricks refraction may be playing in high altitudes. Now, if an observation is taken from a low station to a high peak, and its altitude is fixed in that way, the error which may be introduced by refraction is considerable. If, on the other hand, the observation can be taken back from that high peak to the point from where the observation was taken, that source of error is entirely eliminated. Not only is it eliminated, but a value for the error induced by refraction is obtained, which will serve a most useful purpose in determining the altitude of other peaks. Now year by year we àre demanding from explorers and from mountaineers more and more close observation, more scientific application to their work than has been hitherto accorded to it. I think you will all agree that in late years we have succeeded in getting more. To me it is marvellous how men who succeed in attaining these great altitudes can ever summrn up the amount of resolution that is necessary in order to take the persistent and constant observations which are necessary for scientific purposes; but in this case we must ask them to take one more. If they will only observe from those high peaks what the angle of depression is to some point from which that angle of elevation has been taken, they will be doing an immense service to scientific surveying. I think in asking this we are really not asking very much, for it is not necessary to convey any very heavy instruments to the tops of peaks for this purpose, so that I hope in future that amongst Himalayan climbers we may find some who will work hand-in-hand with the professional surveyors in India, and give us real assistance by their observations. Dr. Longstaff has referred to the ascent of Kabru by Mr. Graham. Now, there was never any doubt whatsoever in the minds of any professional surveyors that Mr. Graham did make a very notable ascent, and did succeed in attaining an altitude which had probably never been reached before. The doubt was whether he had ever actually succeeded in reaching that particular peak which he claimed to have reached, and the points on which the doubt arose were not exactly those describad by the Chairman. I was here when Mr. Graham's lecture was read, and my conviction was that he had not quite succeeded in identifying his own position. It is quite clear from what we have heard to-night that, whatever point he reached, he did not succeed in identifying Mount Everest, and as he said that he found elsewhere, on looking round him, that the trigonometrical survey of India was all wrong, and that there were mountains where there ought to be valleys, and valleys where there ought to be mountain ranges, there still remains to my mind some explanation necessary for this very extraordinary phenomenon. Is it possible that, whilst he failed to recognize the peaks around him from Kabru, he was actually on the point he supposed himself to occupy? I do not know whether after all these years that doubt will ever be quite satisfactorily cleared up, but it would have been in those days an immense advantage to him had he possessed what Dr. Longstaff possesses-photographic apparatus, and a photographer capable of illustrating the fact that he was on the top of the peak. I have nothing more to say, except to join with others in congratulating Dr. Longstaff on what is certainly a very remarkable and will be a very memorable ascent.

Mr. Freshfield : I propose to call on Sir Martin Conway, but I would first make one remark in reply to Sir T. Holdich's criticism with regard to what I just said about trigonometrical altitudes. In describing them as indisputable, I meant

$$
\text { No. IV.-APRIL, 1908.] }
$$




\section{MOUNTAINEERING EXPEDITION TO HIMALAYA OF GARHWAL.}

relatively final. I must point out that twenty years ago, after consultation with Mr. Whymper, I criticized the determination of 29002 feet given for the highest mountain in the world, and suggested that until it had been measured from some points where the effects of refraction were likely to be less serious than in the plains of India, its height could not be considered as absolutely fixed.

Now, I want to ask Sir Martin Conway to tell us something about the socalled nieve penitente. You may recollect that two months ago Dr. Workman described having seen in the Himalaya a series of snow-pinnacles similar to those which have been very minutely described by Sir Martin Conway in the Andes. I do not know if Sir Martin is aware of it, but they were seen before him by another South American traveller, who not only found a collection of those extraordinary snow-pillars, but one of them which served as a pedestal for the frozen carcass of a dead horse, what I may call a cheval perché. No doubt the unfortunate animal had perished in the snow in the winter. The traveller in question was Dr. Darwin. I hope Sir Martin Conway will be able to tell us whether the phenomena described by Dr. Workman seem to him similar to those which he saw in the Andes, and also whether he accepts Dr. Workman's description of their causes : first wind, and then sunshine. I would suggest that, if these snow-pillars exist in other regions than the Andes, we should find some English and less far-fetched term to describe them. That of nieve penitente was derived from a fanciful resemblance to a procession of white-robed penitents.*

Sir Martin Conway: At this late hour, I am afraid it would be impossible to go very deeply into this question of nieve penitente, and I think I should hardly be justified in referring to it at all, if it were not that in one of the photographs, taken, I believe, on Dr. Longstaff's former expedition, there seemed to me to be some appearance of rudimentary nieves in the foreground. I saw no examples in the Karakorams, and I have heard of none observed in the Himalayas except by Dr. Workman in the Nun Kun range. It is almost only, so far as I know, in South America, and within certain definite limits of latitude, that they occur. They are certainly a phenomenon confined within regions of low latitude, and they have nothing whatever to do with the wind. If they were caused by winds, they would have been found in polar regions. They are caused undoubtedly by the melting effect of a relatively vertical sun. It is impossible to describe very briefly and without illustration the manner of their origin, but it has been completely and satisfactorily accounted for. One peculiarity that they have is that the major axis of their horizontal section lies always approximately east and west, unless there should be mountains that shade them from the morning or evening sun, when their axes may be somewhat twisted towards south-east or south-west. It was observing this twist and the cause for it that first opened my eyes to the true origin of nieve penitente; the explanation I gave has since been generally accepted.

Prof. Garwoon: In spite of the early-closing rule mentioned by the President, I carnot refrain from adding my congratulations to those which have already been offered to Dr. Longstaff and his companions. There are many points of great interest in the paper. I will to-night allude to only one of these, namely, the character of the valleys below the snow-line, shown on the screen. I think that every one must agree that they are essentially water-cut gorges, and that ice had little or nothing to do with their formation. Again, that stream which appeared to cross a watershed seems to point unmistakably to a phenomenon that we noticed also in the

* For observations of this phenomenon in the Andes and on Kilimanjaro and a discussion of its origin, see Zeitschrift der Gesellschaft für Erdkunde zu Berlin, 1908, No. 2, and also p. 449 of the present number. 
Sikhim Himalayas, namely, the evidence of an elevation of the whole mountain group at a recent date. The rivers here also appear to have received additional erosive power so as to enable them to cut those wonderful gorges, some of which, I think the author said, were 1700 feet deep. The fact that they have not been widened by atmospheric agents points conclusively to their very recent origin. The retreat of the glaciers shown also in this district is another point of great interest. The presence of "hanging" valleys occurring in the main valleys themselves is a most suggestive phenomenon, and one to which I recently called attention in the Alps. It is very instructive to find the same thing here, proving again that glaciers must, till recently, have protected their beds from the downward erosion by water such as took place in the valley below the termination of the glacier. At this late hour I will only once more add my congratulations on this very admirable expedition.

Mr. Freshfield : We have had a very interesting paper, followed by an interesting and important discussion, in which various points of scientific interest have been raised. I have already informally expressed the thanks of the Society to the reader of the paper, Dr. Longstaff.

Dr. LoNGSTAFF : I am afraid I have not made it clear that I was not the leader of the expedition. We all three worked together to the best of our abilities, but if any one of us deserves the title it is Bruce. I will only mention one other matter : Graham's reference to the irreconcilability of his maps with the actual configuration of the country applies to the Rishi valley and not to anything that he saw from Kabru. I would add that our largest cameras were quarter-plate size, as every ounce has to be considered when coolies are not available.

\section{FURTHER EXPLORATION IN THE TIAN-SHAN MOUNTAINS.*}

By Dr. GOTTFRIED MERZBACHER.

The rigour of winter has for some time interrupted my scientific pursuits and forced me to take up quarters here. I make use of the opportunity to communicate some particulars respecting the course of my expedition down to date.

My departure from Munich was made on April 17, 1907, in company with H.R.H. Prince Arnulf of Bavaria, who, chiefly for the sake of the big game abounding in their valleys, had determined to travel in the Tian-Shan. The impulse to the journey came chiefly from the Prince. The invitation to join him with which he honoured me was, however, all the more grateful to me inasmuch as I had for some quite considerable time been cherishing the wish to follow up my researches in the Tian-Shan, and as in a most generous manner His Royal Highness rendered the prosecution of my scientific pursuits practicable. Unhappily His Royal Highness, after a happy hunting expedition pursued without adverse incident of any consequence, and after his return in complete health to Europe, succumbed at Venice, on October 18 last year, to inflammation of the lungs. The early and unexpected death

* Dated “Kulja, February 9, 1908." 